\title{
EXPLORING AN INTEGRATED PATHWAY FOR SUSTAINABLE URBAN DEVELOPMENT OF REFUGEE CAMP CITIES AND INFORMAL SETTLEMENTS
}

\author{
MAHESH KESWANI \\ Centre for Research in Architecture, Urbanism \& Design (CIAUD), University of Lisbon, Portugal
}

\begin{abstract}
More than half the world's population live in urban areas, and this number is expected to increase substantially by 2050. It, however, does not include temporary settlements stemming from forced displacement, now housing 82 million people worldwide. In many ways, refugee camps and cities face similar population dynamics, social issues, and environmental challenges such as the sustainability of resources, food security, sanitation and water management, sustainable energy, and waste disposal. But informal settlements, like Kutupalong Refugee Camp (KRC) in Bangladesh with almost a million displaced people, continue to slip through the cracks. Planners must acknowledge and plan for these urban settlements building their own organizational structures and economies. This paper reflects on whether the established principles of urbanism can form the basis of long-term developmental planning in spaces of refuge. It evaluates refugee camp cities through the lens of five urban dimensions and investigates innovative and integrated approaches to fill identified gaps. Two case studies undergo a meta-analysis from a "humanitarian urbanism" perspective to understand the process through which they are growing (KRC, Bangladesh) or have evolved (Amman, Jordan). Given the recurring nature of forced migration and burgeoning urbanization challenges of this century, the discussion hopes to spawn viable multiscale and multidimensional interventions in the future.

Keywords: refugee camp-city, informal settlements, humanitarian planning, urbanization, sustainable development.
\end{abstract}

\section{INTRODUCTION}

In 2018, more than half of the world's population lived in urban settlements. By 2050, urban areas are projected to house $68 \%$ of people globally [1]. This number, however, does not include those living in temporary settlements stemming from forced displacement, and it now stands at 82.4 million people [2]. Because the world's urban areas will absorb or interact with a big percentage of the displaced people eventually via assimilation, integration, or resettlement [3], the link between planned urban settlements such as cities and informal settlements associated with forced displacement is a strong one. For specificity related to this paper, it is also important to define and differentiate between voluntary and forced migration (and between migrants and refugees/asylum seekers). Informal settlements are often reviewed in the context of informal housing, but their categories are wide ranging. For this paper, "informal settlements" (IS) refer to migrant and refugee-majority settlements, and together with camp cities (CC) will be abbreviated as CCIS henceforth. Host Communities will utilize the acronym $\mathrm{HC}$.

The UN 2030 Sustainable Development Goal 11 aims to "make cities and human settlements inclusive, safe, resilient and sustainable" [4], but most of these spaces fail to meet these criteria on multiple counts [5]. Most CCIS carry the additional burden of physical, social, and economic segregation, and have drawn special attention from world bodies. United Nations High Commission for Refugees (UNHCR) has published a manual called the UNHCR Handbook [6] with technical specifications for transient settlements such as refugee camps. However, the immense scale of the current migratory movements appears to render older manuals and urban plans inadequate [7]. Seemingly transient settlements are now the 
size of intermediate cities; a prime example is the Kutupalong Refugee Camp (KRC) in Bangladesh housing almost a million people between 27 scattered sub-camps. The phenomenon of protracted displacement and the evolution of temporary camps into permanent CCIS has led to an emerging consensus that these spaces are increasingly mimicking urban agglomerations in terms of urbanization challenges. Killian Kleinschmidt, one of the world's leading authorities on humanitarian aid, even calls them "the cities of tomorrow" [8]. The secondary challenges with CCIS are multidimensional: the "right to urbanism", official recognition, spatial limitations, lack of freedom of movement, spatial segregation with social exclusion, perennial dependence on outside actors, fragile ecosystems, and greater susceptibility to disasters. Because the biggest CCIS have sprouted this century [9], there are few investigative studies related to integrated planning approaches that go beyond addressing the physiological and safety needs at a rudimentary level.

This paper attempts to challenge the current narrative of refugee CCIS as state-planned geopolitical assemblies and explore holistic, interdisciplinary approaches combining the social sciences, humanities, and urban planning to encourage innovative and measurable solutions in sustainably developing them. With two frames of reference in Jordan and Bangladesh, this paper will broadly cover the complex and intertwined layers based on five established dimensions (and highlighted sub-dimensions) of urbanism within the CCIS setting: governance, infrastructure, society, environment, and economy (Fig. 1).



Figure 1: Dimensions of urbanism (Source: UCL) and CCIS juxtaposition (Source: Author).

\subsection{Selection of case studies}

Jordan has the second highest refugee to citizen ratio in the world [10] and has developed into a country defined strongly by its refugees over the last 70 years. The role of territorial players has never been more prominent: refugees (along with government institutions and NGOs) have been actors with economic, political, and social agency in playing an integral role in the Jordanian state's socio-spatial reconfiguration since its independence in 1946. By eliminating the dichotomy between city and camps, Amman makes the case for an integrated approach to urban development. As a city that has grown ten-fold over the last seven decades 
on the back of heavy refugee influx, Amman comes closest to the scaled-up response that a million-strong burgeoning CCIS in Bangladesh can utilize in its development.

The district of Cox's Bazar in Bangladesh hosts the world's largest refugee camp and, in terms of population, meets the requirement of a city. The settlement is in the infancy of what appears to be a complex development path following the abrupt establishment of scattered camps to accommodate the heavy influx of Rohingya refugees from Myanmar in 2017. As opposed to Amman which has documented a steady population growth trajectory due to spaced-out trigger events, Cox's Bazar was deluged by an overwhelming number of refugees seemingly overnight. Between 2017 and 2019, more than 700,000 refugees joined 200,000 Rohingya who had fled Myanmar years ago and lived among the 2.5 million strong host community [11]. Another important statistic is that more than $50 \%$ of the camps' residents are children, and humanitarian responses should include long-term development solutions catering to this demographic. Adding to the urgency, 75,000 children have been born in the camps over the last 3 years; with an implied population growth rate of $10 \%$, the camps could see a two-fold increase over the next decade and a four-fold increase in less than 20 years.

The assessment of the locations against each dimension can offer a better understanding of the dynamics in play and the implementation of macro, meso, and micro strategies by relevant actors in the two countries. This can allow for an integrated and replicable plan to guide the urban transformation of CCIS and reflect New Urban Agenda principles and SDGs.

\section{DIMENSION ONE: URBAN GOVERNANCE}

The Refugee Convention of 1951, and the subsequent 1967 Protocol, broadly required that international laws legalize and institutionalize the existence of refugees, define the roles and responsibilities of receiving states, and ensure sufficient humanitarian, social and economic support for vulnerable forcibly displaced people [12]. Jordan and Bangladesh are both nonsignatories to the Convention but their approaches to address the refugee crises strikingly differ. Over the last six decades, Jordan has encouraged its agencies to work with the UN and other IGOs to craft a MOU on addressing its refugee influx and integrating CCIS into its growing economy. Since the establishment of the Rohingya camps in 2017, Bangladesh has opted to isolate the CCIS politically and physically and has placed severe restrictions on the resettlement services IGOs and NGOs can offer. them.

Fig. 2 illustrates the sub-dimensions of Urban Governance and key SDGs associated with

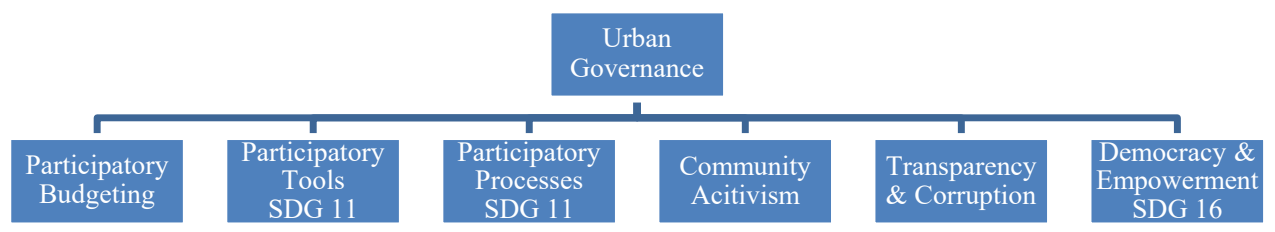

Figure 2: Organizational chart with Governance sub-dimensions and associated SDGs. (Source: Author.)

\subsection{Challenges and strategies}

Between 1951 and 1967, Jordan committed to taking in Palestinian refugees based on regional and national laws with support from the newly created UN. Between 1967 and 2004, the country continued to absorb waves of refugees from multiple Middle East trigger events 
with UNHCR support and on the principles of The Arab Charter of Human Rights. The government created the Ministry of Planning and International Cooperation (MOPIC) and the non-profit Jordan Hashemite Organization (JHCO) to coordinate with UNHCR on joint responses in specific sectors: "education, health, environment, justice, livelihood and food security, local governance and municipal services, shelters, social protection, transportation, wash and management" [13]. For its part, UNHCR coordinated its efforts with other UN branches such as World Food Programme (WFP), the UN Entity for Gender Equality and the Empowerment of Women, the UN Children's Fund, and the UN Office for Project Services [13]. The result was a Joint Response Plan which, despite some economic shortcomings, laid the foundation for refugee-related policy development. With international support, the 2016 Jordan Compact has been strengthening these protections and addressing the shortcomings with game-changing reforms and innovative mechanisms to expand economic opportunities for the CCIS and HC.

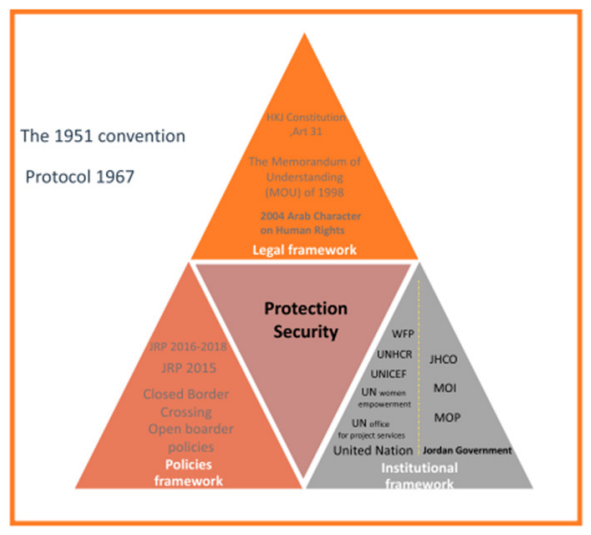

Figure 3: Jordanian Governance framework to manage refugee crisis. (Source: $M O P I C$, 2015.)

In contrast to Jordan's comprehensive response plan which has undergone several iterations, Bangladesh's organizational structure is relatively new. The key actors are the Government of Bangladesh (GoB), the Bangladeshi Army, the Majhi system, and IGOs such as UNHCR et al for CCIS management [14]. On the government's behalf, the Ministry of Disaster Management and Relief (MoDMR) is responsible for the overall governance of CCIS, and the Refugee Relief and Repatriation Commissioner (RRRC) represents the MoDMR in the Rohingya response. The Bangladeshi Army is/was the first responder to the crisis, and participates in evacuation, rescue, relief, and rehabilitation operations [14] in addition to overseeing road construction and infrastructure. For immediate assistance, the army also introduced the country's existing Majhi system to the response plan. Majhis, who act as local spokespersons for the Rohingya, were initially assigned to support the estimation of refugee populations, organization of distribution efforts, and channelling communication to the refugee community [14]. As the Rohingya population exploded, their roles were expanded to include dispute mediation, camp security, and assessment sources for humanitarian organizations. With informal but extensive power and responsibility over Camp Blocks and Camp-in-Charges, majhis have been the focal points of camp governance. The 
roles of IGOs like UNHCR have been limited to CCIS maintenance and organization, and the benefits of an organizational structure with participatory processes are yet to be felt.

In the absence of a true collaborative, the system has had to deal with lack of accountability and protection. Over the years, the majhi system (with a $90 \%$ male demographic) has been the subject of investigation of abuse of power and exploitation [15]. To ensure true representation at the micro level, the Joint Response Plan is experimenting with two community participation initiatives. The first created Para Development Committees (PDCs) to engage both refugees and host communities, and they included representatives from both parties. The PDCs identify common needs and work out solutions, act as dispute mediators, and liaise with the aids organizations and local authorities to coordinate on provision of services and resource distribution. The downside is that the PDC model is currently limited to the collective sites only and is not implemented in camps with $100 \%$ refugee populations. To address this, aid organizations have developed a second initiative utilizing a participatory townhouse-styled model which runs parallel to the majhi system. With all-round participation, the forums open channels of direct communication, assist with programming, and generally foster self-organization and self-determination among refugees.

In conclusion, micro governance has been improving since 2018, but meso and macro structures require changing the lens of a government that views long-term development as an obstacle to repatriation.

\section{DIMENSION TWO: URBAN ECONOMY}

With a GDP of $\$ 353$ billion [16], and a need for $\$ 1$ billion annually in humanitarian assistance for the camps, Bangladesh has been struggling to meet the demands of the refugee crisis. The dominant sectors are agriculture and industry which account for $32 \%$ of the country's GDP and employ $60 \%$ of the total workforce [17]. In comparison, Jordan's GDP has averaged just \$12.2 billion from 1965 until 2020, reaching an all-time high of 43.74 USD billion in 2019 and a record low of 0.56 USD billion in 1968 [16] when its refugee population started exploding. The role of the informal economy in the development of CCIS requires a special mention. The informal economy is a global phenomenon and the backbone of third world economies. The International Labour Organization (ILO) estimates that $60 \%$ of the world's labour force participates in the informal sector, and that this number is more than $85 \%$ in Bangladesh. CCIS have always operated within shadow mechanisms in emerging economies; the system allows state actors and relief organizations to create and sustain multiyear relief operational plans by stretching limited budgets. Innovative mechanisms to trigger growth are the need of the hour.

Fig. 4 illustrates the sub-dimensions of Urban Economy and key SDGs associated with them.

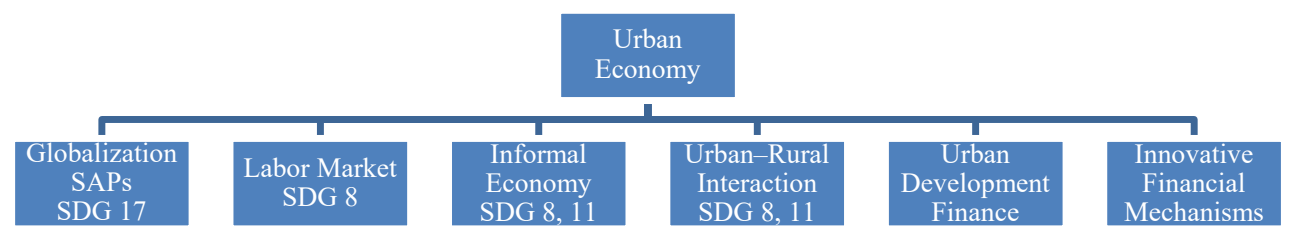

Figure 4: Organizational chart of economy sub-dimensions with associated SDGs. (Source: Author.) 


\subsection{Challenges and strategies}

In Amman, the material and socio-cultural transformation of CCIS into city neighbourhoods was primarily funded by relief organizations such as UNRWA within their boundaries while Greater Amman Municipality (GAM) played a pivotal role in infrastructure development around their peripheries. The Jordan Compact of 2006 was a gamechanger in how host countries and IGOs responded to these challenges. Utilizing a combination of concessional financing, creation of special economic zones (SEZs), and beyond-aid incentives while simultaneously advancing legislative policies to benefit CCIS and HC, the Jordanian government has built a viable roadmap for inclusive and sustainable growth. The compact has had its share of failures as well: lack of refugees' perspectives at the outset, continued financial barriers and quality of services resulting in lower school enrolment, and non-access to critical sectors and self-employment for the refugees. The London Initiative of 2019 looks to address them with national policy tweaking, additional funding, and opening the labour market, but the results will not be visible for another decade.

GoB's decision to designate the majority of the Rohingya as Forcibly Displaced Myanmar Nationals (FDMNs) versus "refugees" has translated into developmental challenges across the entire urban spectrum. The meso and macro level impacts are forceful and, as with typical socioeconomic analyses, are associated with other related sectors such as governance, infrastructure, health, and education among others. In the absence of a compact in Bangladesh, all these sectors lack the framework for sustainable development. In conjunction with other sectoral changes, a dual-pronged approach using UN-Habitat's economic toolkit can set the tone. The first prong involves utilizing flexible instruments such as land-based finance with a socially inclusive approach to land tenure that provides equal rights to landowners and the land occupants, and the second encourages innovative financing arrangements and Public-Private-People-Partnerships (PPPPs) for CCIS. Fig. 5 illustrates the financing framework to guide the transformation.

The key principles of the financing framework

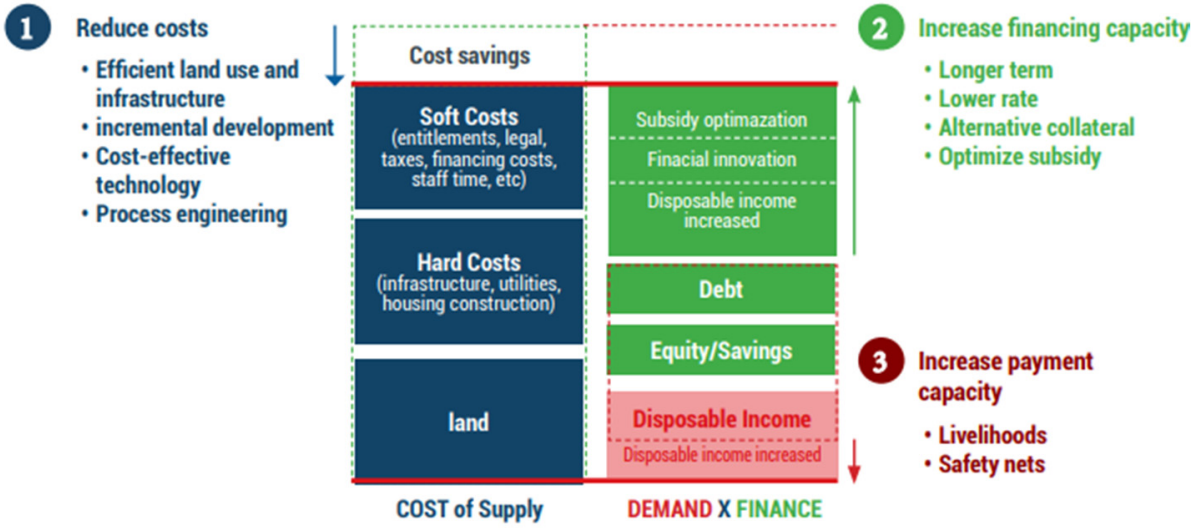

Figure 5: Sustainable financing framework. (Source: UN-Habitat, 2020.)

The Joint Response Plan of 2019 aims to boost public and private sector investment for economic opportunities and job growth. Recently, the Bangladesh Economic Zones 
Authority (BEZA) has designated several zones across the country, including Cox's Bazar, to assist with these objectives. With agriculture and industry accounting for a third of the country's GDP, the focus should be on funding local value chains such as fishing, agriculture and agriwaste-processing, and clean energy, all of which can also help meet multiple SDG objectives. As an example, more than 5,000 acres of forest reserves in Cox's Bazar has been rendered unusable due to deforestation and hill cutting for shelter construction (resulting in landslides). Depletion of marine resources has also weakened the fishing industry, which employs nearly one in three persons [17]. Cash for work (CFW) programs for the refugee population, along with training and support in a new industry, can form the basis for a sustainable informal and circular economy until the legislative hurdles are cleared for employment outside the CCIS boundaries. New manufacturing facilities for sustainable building material from two sources (rice straw/husk particleboards from residue of rice production processes and prolific forest bamboo from the region) can provide additional opportunities. Both these products involve working with farmers, informal laborers, and the establishment of production facilities (mill, dryer, mat former, and hot press) to boost the local economy, and can lead a transition to a bio-based economy that benefits the CCIS and $\mathrm{HC}$ of Cox's Bazar as well as the entire region. With tourism also a big revenue generator in the coastal area, the government has an eye on the future with investment in a new railway line connecting Dhaka to Cox's Bazar and set to open in 2022.

In conclusion, the shift in the JRP from short-term humanitarian programming towards longer sustainable development is a welcome start. National policy changes related to refugee-resettlement, if implemented by a reluctant government, can open the doors for an effective "Bangladesh Compact" as the first big step towards socio-economic growth.

\section{DIMENSION THREE: URBAN ENVIRONMENT}

Prior to the start of the Syrian refugee crisis in 2011, Jordan was already struggling with water scarcity, rapid population growth and urbanization, lax agricultural industry standards, and deteriorating air quality. In Bangladesh, the situation is worse. The refugee influx into the Cox's Bazar district has led to a detrimental effect on the environment, the region's natural ecosystem, and the health and physical wellbeing of the CCIS and HC. In addition, its low-elevation location on the Bay of Bengal makes it susceptible to effects of climate change, with more than 500,000 lives lost from four cyclones in the last 50 years. Sea level rise, flooding, erosion, landslides, and salinization among others have already caused major displacements, and one in every seven people will be displaced by 2050 [18].

Fig. 6 illustrates the sub-dimensions of Urban Environment and key SDGs associated with them.

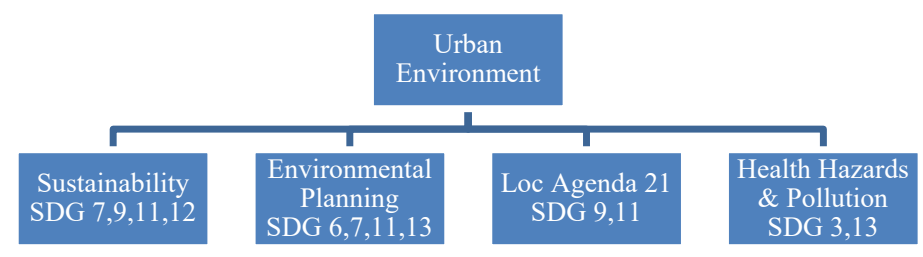

Figure 6: Organizational chart of Environment sub-dimensions with associated SDGs. (Source: Author.) 


\subsection{Challenges and strategies}

During the 1991 Gulf war, more than 1.3 million refugees (primarily herders) entered Jordan with 1.8 million animals who grazed down 7.1 million hectares of rangelands, resulting in serious habitat degradation [19]. The addition of more than 1.5 million Syrian refugees has added to the country's environment cost. In 2014, Jordan set up a national response platform to bring together government ministries, UN agencies, and NGOs to tackle its environmental problems. An assessment carried out by the joint venture called for "mainstreaming environmental factors into refugee projects is crucial to reduce long-term harm and minimize community grievances" [19]. A similar assessment of impact on refugee communities carried out in Bangladesh [20] identified multiple key risks/indicators for 13 environmental components.

Hill cutting for shelter construction and firewood for cooking has resulted in 5,000 acres of forest degradation and habitat destruction in the Cox's Bazar region. Soil erosion aided by climatic flooding has resulted in several landslides leading to loss of lives. Since tube wells are the primary source of water, the rate of water depletion is alarmingly high; deep wells are being researched but the shallow aquifer is expected to exhaust its resources soon. In addition, leakage and overflow from thousands of latrines close to water points has caused ground water contamination leading to increased public health risk. Loss of vegetation cover has reduced water retaining capacity and has decreased freshwater sourcing from the watershed. The hilly area and impermeable subsoil also restrict boring for ground water [20].

The wide-ranging concerns have prompted the GoB to team up with United Nations Development Program (UNDP) and adopt its Social and Environment Standards (SES) towards planning short and long-term protection for its fragile ecosystem. The Environment Management and Mitigation Plan identifies national and international partners and 18 impact areas and includes recommended actions to collectively address natural and manmade disasters in the region with a history of occurrences of landslides, flash floods, cyclones, earthquakes, and tidal surges. Short-term actions include distribution of cooking gas and alternative fuels to households (this has already decreased the deforestation rate by $50 \%$ ), protection of water sources from excreta pollution, and improvement of sanitation, solid waste collection and disposition processes. Longer term actions require geophysical investigations to identify deep aquifers for piped water supply, scale up disinfecting treatment facilities for 2.5 million residents, preparation of contingency plans for natural emergencies, engineering and biological restatement of soils and terrain to minimize landslides, full vaccine coverage and reduction in population density to address communicable diseases, afforestation and reforestation through social forestry plantation and agroforestry, protection of national forest lands and parks including the Teknaf Wildlife Sanctuary and Himchari National Park, and habitat protection for wildlife [20]. Follow-up actions will require a detailed monitoring plan to verify the intended effects, detect environmental changes and trends, and allow for adaptive management.

In conclusion, the key to environmental planning of CCIS and $\mathrm{HC}$ is a plan that considers land and resource use patterns of both communities, the cumulative short- and long-term impacts of development on the ecosystem, and enhancement of other areas of the country to ensure no net loss in biodiversity. And if the plan is implemented under the umbrella of the UN Humanitarian Response Plan process, monitoring the CCIS using SDG indicators and benchmarks can demonstrate quantifiable progress. 


\section{DIMENSION FOUR: URBAN SOCIETY}

A World Bank Report in 2018 studying "social cohesion" in the context of forced displacement noted that various factors such as the societal dynamics between CCIS and HC, spatial arrangements, duration of displacement, and perceptions of identity can affect the outcome of a proposed approach [21]. A successful long-term development strategy requires understanding of the five dimensions of social cohesion: belonging, inclusion, participation, recognition, and legitimacy.

Fig. 7 illustrates the sub-dimensions of Urban Society and key SDGs associated with them.

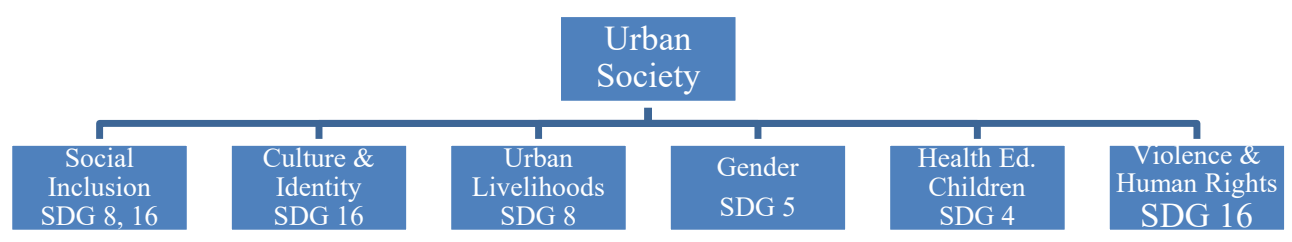

Figure 7: Organizational chart of Society sub-dimensions with associated SDGs. (Source: Author.)

\subsection{Challenges and strategies}

The characteristics of the nature of displacement in the two countries have led to varying approaches and outcomes. From the outset, Jordan's open and self-settled camps based on voluntary co-habitation with host communities differed sharply from Bangladesh's closed, restrictive CCIS with minimal or zero co-habitation opportunities. In response to the Syrian refugee crisis, the Jordan Emergency Services and Social Resilience Project (JERSSP) was established with a mission "to foster social cohesion through voice and participation" [22]. The project was context-specific and worked at the community level with established UNDP parameters like demographic profile, economic indicators, and social indicators to propose long terms solutions.

Bangladesh's challenge is bigger: being a closed camp with minimal interaction with host communities, the Rohingya have been physically isolated and socially segregated since 2017 due to national policy reasons. Fleeing from violence and human rights abuses, reports have found that even livelihood tasks such as collecting firewood for cooking exposes men, women, and children to significant risk, including sexual assault. Intimidation of Rohingya women appointed to outreach positions is another concern. [23]. With women and children accounting for $75 \%$ of the camps' population, their safety and education have been prioritized. In response to these challenges, IGOs and NGOs have proposed, and are executing community-level solutions such as designated safe spaces for women and children, and community kitchens which are treated as alternative safe spaces for women to voice concerns and exchange information [23]. The government has also contributed by providing LPG cooking cylinders in 2018 to reduce deforestation and enhance safety. Besides these protection concerns, issues related to culture and identity and education of children remain. As the Urban Infrastructure section indicates, preservation of the Rohingya heritage as a talking point has only begun earlier this year. The attention to education has also taken a new turn since April 2020 when, in response to global demand for a formal education for the 
camps' 400,000 children, a pilot program with a Myanmar curriculum was introduced for grades 6 through 9 [24].

Using a versatile tool such as the UNDP-developed Social Cohesion and Reconciliation (SCORE) Index to evaluate vulnerability factors and measure different components of social cohesion in the camps is the next logical step towards scaling up resilience capacity. The SCORE Content Framework focuses on five dimensions of societal functioning: human capability, human security, community cohesion and harmonious group relations, institutional and economic development, and meaningful civil participation and engagement [25]. As Bangladesh, Myanmar, and the rest of the world work towards a political solution to the crisis, engagement in advocacy of these societal challenges should continue unabated.

\section{DIMENSION FIVE: URBAN INFRASTRUCTURE}

Refugee camps and CCIS are almost always associated with rapid and uncontrolled urban development, inefficient land use, and single-year planning by political default as opposed to long-term approaches. Jordan and Bangladesh have utilized divergent planning approaches in dealing with their respective crises, each with micro, meso, and macro repercussions on urban development of CCIS and HC.

Fig. 8 illustrates the sub-dimensions of Urban Infrastructure and key SDGs associated with them.

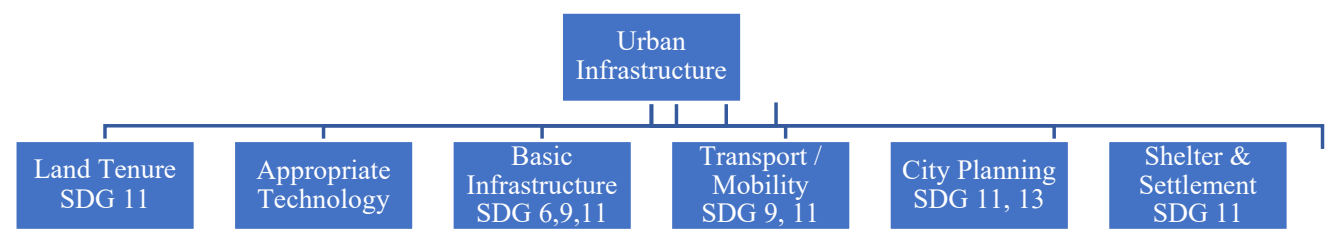

Figure 8: Organizational chart of Urban Infrastructure sub-dimensions with associated SDGs. (Source: Author.)

\subsection{Challenges and strategies}

The first connection between spatiality and its camps and marginalized informal settlements was documented in Amman's 1987 Master Plan (Fig. 9) which clearly demarcates its affluent western half from the poorer eastern half with low-income residents and refugees. Between the 1970 s and the early 2000 s, the built environment had materially and spatially transformed itself and begun exhibiting the complexity of a peri urban area. The shift in thinking is clearly visible in GAM's Amman Master Plan of 2008 (Fig. 9) which included specific housing zones for refugees/public housing and has spawned an unorthodox approach to metropolitan, urban, and community planning.

The planning occurred simultaneously on all three scales [26]. The objective was to not only compress the typical 5 year trickle down schedule from top-down metropolitan to community planning but also encourage active citizen participation for bottom-up interventions (critical for bringing vulnerable neighbourhoods into the planning fold). At the macro and meso levels, the "two Ammans" eventually fused into one and the city centre gravitated eastward from western Amman, completing a multi-decade spatial transformation.

Bangladesh's one-year planning strategy, weak building capacity, and rapid urbanization calls for swift, integrated spatial planning via a meso Urban Structure Plan that works towards 

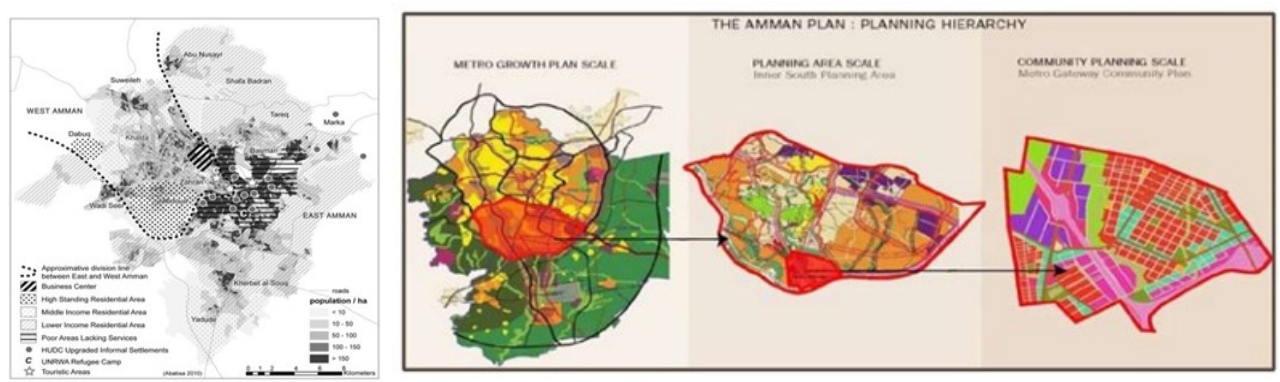

Figure 9: (Left) Divide between West and East Amman. (Source: GAM Master Plan, 1987.) (Right) The Amman Plan: Planning hierarchy diagram. (Source: GAM, 2008.)

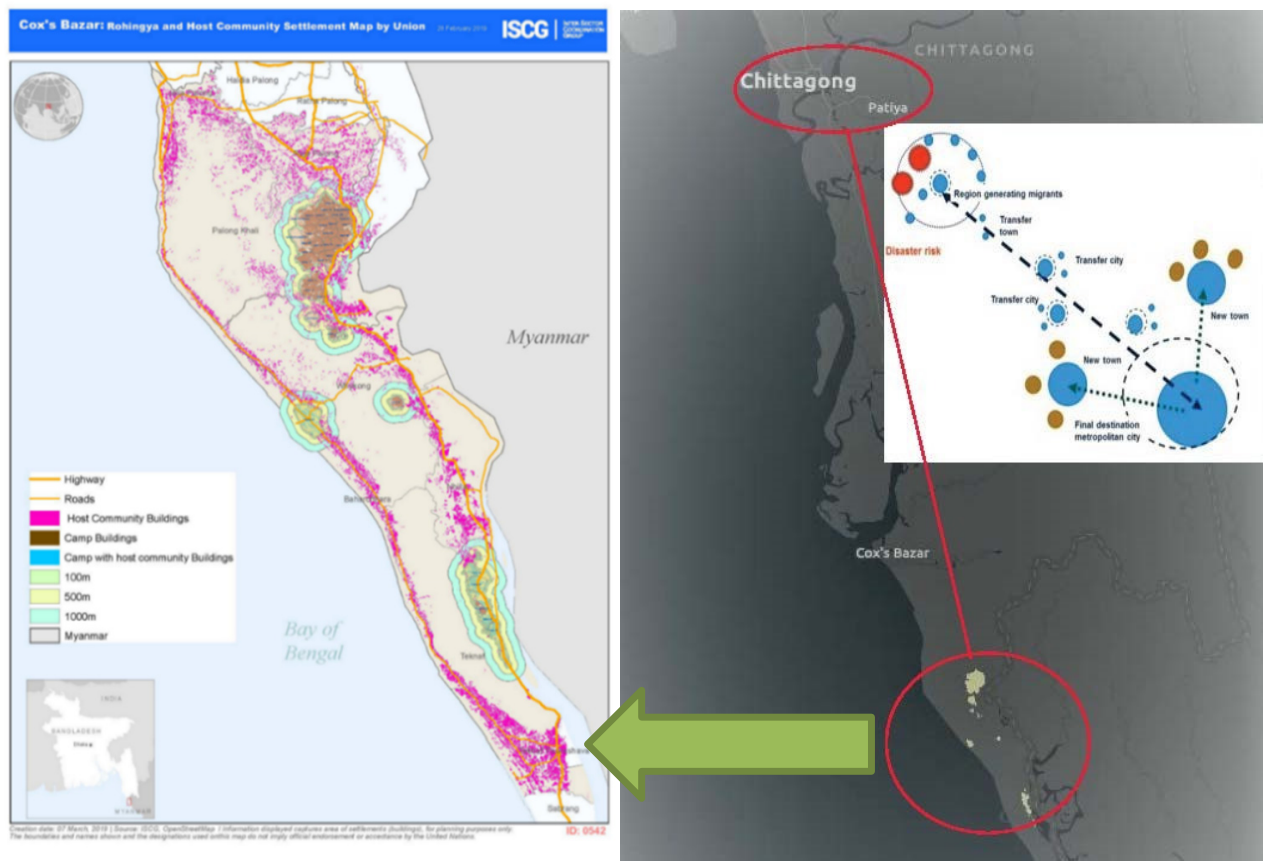

Figure 10: (Left) Cox's Bazar, Bangladesh, with camps and host communities. (Source: $I S C G$, 2019.) (Right) Strategy for migrant corridors. (Source: UN/POP/EGM, Murillo, 2017, Author.)

a common vision, ropes in all relevant state and non-state actors and a micro Urban Design Plan that uses extensive participatory tools and processes at the CCIS and HC level. A structure plan at the meso level can, as shown in Fig. 10, implement UN strategies for developing a regional migrant corridor [27] connecting 1 million refugees and 4 million residents (including 2 million from Cox's Bazar) to Chittagong. 
Micro ethnographic interventions and spaces of cultural expression are critical components of socially inclusive urban design. In May 2021, the Rohingya Cultural Memory Centre (RCMC) opened its doors with support from the UN and other IGOs [28]. The space aims to express Rohingya culture, and the centre offers psychosocial support through art therapy and activities addressing the key factor affecting refugees' well-being: identity crisis. Another urban design intervention can incorporate existing information on infrastructure and amenities to produce inclusive and accessible public spaces to promote social healing based on common denominators. For example, superimposing existing worship facilities on a map with can locate a central place of worship (CPOW in Fig. 11) tied to the memory centre. The faith-based interventional methodology can be solidified further through architectural form (mosque-conjuring dome?) and material messaging impermanence and sustainability (soil, bamboo, rice strawboards?).

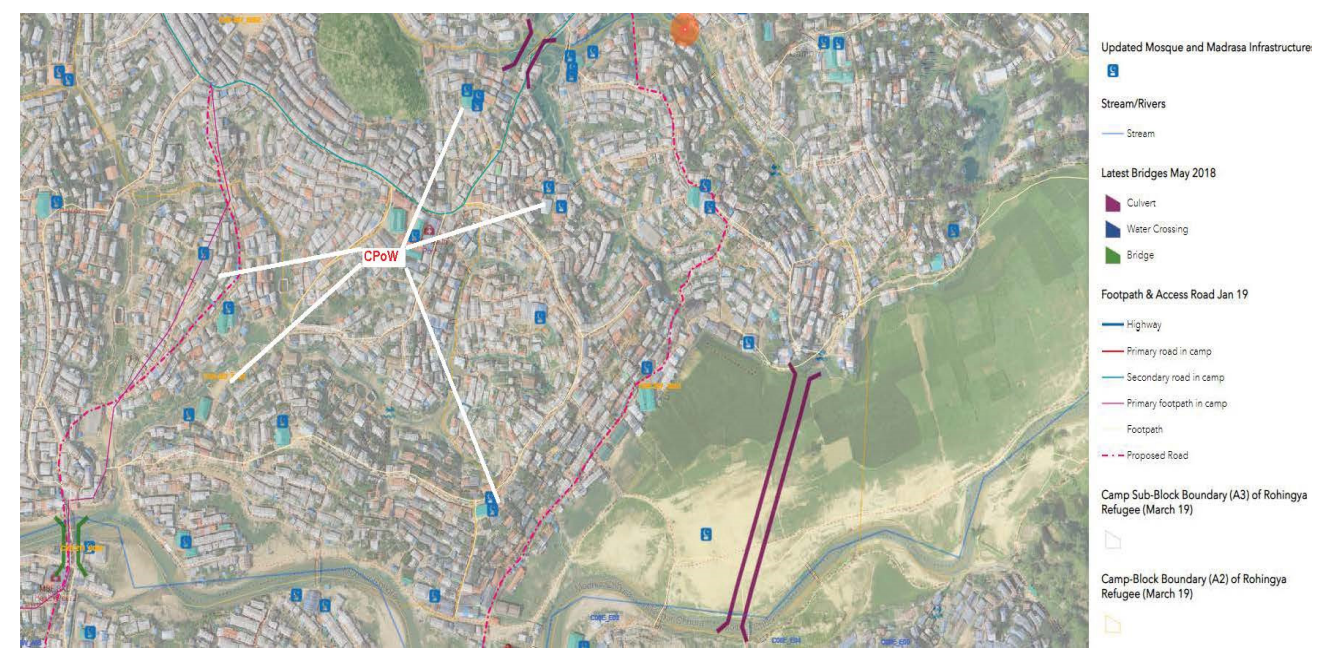

Figure 11: Partial map of Camps 7 and 8 in Cox's Bazar, Bangladesh, with legend and layers (Source: ISCG, 2019) with author's designation of CPOW intervention.

In conclusion, there are signs of progress at the urban design level as the creation of the RCMC has shown, but a longer term plan for regional regeneration is needed. Programs such as UN Habitat's SDG Project Assessment Tool and City-Scale Assessment Tool can assist with sustainability frameworks.

\section{DISCUSSION}

The analyses of these intertwining dimensions are as critical to the sustainable development of camp-cities as they are to traditional cities and urban agglomerations. Every dimension interacts with another to generate viable solutions. Governance must work with Economy to create innovative and accessible financing mechanisms. Infrastructure (Shelter Planning) must collaborate with Economy and Environment towards sustainability and livelihood. For example, establishing an industry which recycles rice straw with a cement mix to form a lowcost sustainable building material can boost the region's informal economy, provide opportunities for CCIS and HC, and reduce air pollution from the open burning of postharvest straw. Infrastructure must also incorporate a governance model adopting 
participatory tools and processes to encourage refugee feedback and support bottom-up approaches. And finally, Infrastructure must incorporate principles of humanitarian urbanism and socio-social development to address trauma-driven societal challenges of forced migration.

An integrated, holistic approach then requires strategic interventions at the macro, meso, and micro levels. At the macro level, an international burden-sharing "Bangladesh Compact" that brings together relevant players and links humanitarian and development needs is required. Players must include the GoB, World Bank, the UN, and other donor governments with an interest in crisis mitigation. The model must achieve three primary objectives: legal recognition of the refugees with "right to the city", easing pressure on Bangladesh through burden and responsibility sharing, and increasing refugee self-reliance by enhancing the informal economy and quality of life. At the meso level, innovative urban regeneration strategies such as developing migrant corridors to sync with regional plans can achieve improved economic, social, and environmental outcomes. At the micro level, urban design approaches targeting CCIS's urban dynamics are key since they influence the production and character of social space. These should include (a) spaces for women and children founded on safety and security, (b) inclusive public spaces promoting identity, belonging, dignity, and cultural heritage preservation, (c) gender-empowering spaces for self-reliance, d) breakingthe-generational-cycle learning spaces for children's education, e) refugee health services for physical healing and mental health from migration-induced trauma. This integrated approach, utilizing SDGs and existing IGO tools, can eventually form the framework for a replicable global template in converting Camp-Cities and Informal Settlements (CCIS) into Integrated Sustainable Settlements (ISS). While the SDGs lay out a vision and a checklist of actions to meet UN goals, this discussion serves as a broader reminder to include the displaced 82.4 million and their informal settlements into the urbanization conversation. At the very least, it aims to increase awareness of the need for trans-disciplinary research. And in the best-case scenario, it can bridge new and existing concepts to spawn innovative strategies in addressing one of the biggest urbanization challenges of this century.

\section{REFERENCES}

[1] UN Habitat, World Cities Report (2020). https://unhabitat.org/World\%20Cities $\% 20$ Report $\% 202020$.

[2] United Nations, High Commission for Refugees (2021). UNHCR Global Trends 2021. https://www.unhcr.org/flagship-reports/globaltrends/.

[3] United Nations, UN Habitat. https://unhabitat.org/topic/migration.

[4] United Nations, Sustainable Development Action 2015. United Nations Sustainable Development. https://www.un.org/sustainabledevelopment/cities/.

[5] United Nations, UN Habitat. World Cities Report 2018, 2020.

[6] United Nations, High Commission for Refugees. Emergency Handbook. https://emergency.unhcr.org/.

[7] United Nations, UN Habitat, World Urban Forum 7 Report, 2014. https://unhabitat.org/sites/default/files/documents/2019-05/wuf7_report.pdf.

[8] Mohdin, A., Quartz, 2015. https://qz.com/560768/when-refugees-camps-last-threegenerations-we-must-accept-theyre-not-going-anywhere/.

[9] United Nations, High Commission for Refugees, 2021. https://www.unrefugees.org/ news/inside-the-world-s-five-largest-refugee-camps/.

[10] United Nations, High Commission for Refugees. Jordan Factsheet, 2021. https://reporting.unhcr.org/sites/default/files/Jordan $\% 20$ country $\% 20$ factsheet $\% 20-\%$ 20February\%202021.pdf. 
[11] United Nations, High Commission for Refugees, Bangladesh Factsheet 2021. https://data2.unhcr.org/en/documents/details/88397.

[12] United Nations, The 1951 Refugee Convention. https://www.unhcr.org/1951-refugeeconvention.html.

[13] MOPIC, Jordan Response Plan for Syrian Crisis 2016-2018. Amman: The Ministry of Planning and International Cooperation, 2015.

[14] ACAPS, 2018. https://www.humanitarianresponse.info/sites/www.humanitarian response.info/files/documents/files/20180606_acaps_npm_report_camp_governance final_0.pdf.

[15] World Food Programme (WFP), 2008. https://documents.wfp.org/stellent/groups/ public/documents/ena/wfp190341.pdf.

[16] International Monetary Fund. https://www.imf.org/en/Countries/BGD.

[17] Bangladesh Bureau of Statistics (BBS), 2018. http://bbs.portal.gov.bd/sites/default/ files/files/bbs.portal.gov.bd/page/a1d32f13_8553_44f1_92e6_8ff80a4ff82e/Banglade sh $\% 20 \% 20$ Statistics-2018.pdf.

[18] Environmental Justice Foundation (EJF). https://ejfoundation.org/reports/climatedisplacement-in-bangladesh.

[19] The Ecologist, 2016. https://theecologist.org/2016/apr/27/jordan-grapplesenvironmental-consequences-its-refugee-crisis.

[20] UNDP. http://www.undp.org/content/bangladesh/docs/Publications/Pub-2018/ Updated/REIRI.pdf.

[21] World Bank Group, 2018. https://documents1.worldbank.org/curated/en/1255215319 81681035/pdf/128640-WP-P163402-PUBLIC-SocialCohesionandForced Displacement.pdf.

[22] ALNAP, 2015. https://www.alnap.org/help-library/jordan-emergency-services-andsocial-resilience-project-jessrp-monitoring-and.

[23] ADH, 2019. https://reliefweb.int/sites/reliefweb.int/files/resources/Evaluation $\% 20 \%$ 20Report_Rohingya_HERE-ADH_2019-04.pdf.

[24] Human Rights Watch (HRW), 2020. https://www.hrw.org/news/2020/01/29/stepforward-10000-rohingya-refugee-children.

[25] SCORE, 2021. https://scoreforpeace.org/en/methodology.

[26] Amman Institute for Urban Development, 2010. http://www.cip-icu.ca/pdf/2010-HM-International-Development.pdf.

[27] Murillo, F., Sustainable Cities, Human Mobility and International Migration: A Concise Report, 2017. https://doi.org/10.18356/a11581d8-en.

[28] UN, IOM, 2020. https://rohingyaculturalmemorycentre.iom.int/. 